\title{
On the distortion and warping of cantilever beams with hollow section
}

\author{
Timo Björk ${ }^{1}$ (D) - Antti Ahola ${ }^{1} \cdot$ Tuomas Skriko $^{1}$ \\ Received: 3 September 2019 / Accepted: 24 April 2020 / Published online: 9 May 2020 \\ (C) The Author(s) 2020
}

\begin{abstract}
This paper deals with the stress analysis of a cantilever box beam subjected to static or fluctuating torsional moment loading. Such beams may have multiple critical locations from the strength point of view; one interesting detail is the cross section where the loading is imposed. However, such details can be typically designed to possess smooth shapes, resulting in moderate stress concentrations, which mean that fatigue failures can be avoided. However, the distortional deformation of the cross section induces transverse bending stresses, which may be detrimental, particularly in welded box beams. In addition, the fixing location where the beam is typically welded to an end plate may become a critical point. This paper presents an analytical approach for calculating the longitudinal stresses due to the warping of the cross section as well as the distortion-induced transverse and longitudinal stresses in rectangular hollow sections. Finite element analyses (FEAs) are carried out to verify the analytical approach to shed light on the critical points in the end plate details with different degrees of weld penetration using the effective notch stress (ENS) concept and to suggest design proposals for an efficient structural detailing of diaphragm plates to decrease the warping behavior.
\end{abstract}

Keywords Distortion · Warping $\cdot$ Secondary warping $\cdot$ Hollow cross section $\cdot$ Welded joints $\cdot$ Ultra-high-strength steel

\section{Introduction}

Rectangular hollow sections (RHSs) usually offer good, or at least moderate, structural performance for beams subjected to various loads, such as axial and shear forces as well as bending and torsional moments. In warping, the cross section of the beam remains in its original shape, whereas in distortion, it will take on a parallelogram shape. Both these deformations cause axial displacements and/or membrane stresses in the beam, but distortion also causes transverse bending stresses in the wall of the cross section. These phenomena are independent degrees of freedom of the beam. Particularly from the fatigue design point of view, the bi-moment causing the warping of the

Recommended for publication by Commission XV-Design, Analysis, and Fabrication of Welded Structures

Timo Björk

timo.bjork@lut.fi

1 Laboratory of Steel Structures, LUT University, P.O. Box 20, 53851 Lappeenranta, Finland cross section and distortional loads of RHS beams is an interesting, but lesser known load condition. The fundamental basics of the primary warping of box beams can be found, e.g., in Ref. [1-4], while the secondary warping of the cross section is covered in Ref. [5-7]. Rubin [8] studied the effect of the corner radius on the primary warping of RHSs, showing that it also causes primary warping in square hollow sections (SHSs). Meanwhile, the distortion of closed cross section has been studied in Ref. [9-12]. Nevertheless, previous studies tend to focus on the theoretical background of the distortion and warping of cross sections, and less attention has been paid to practical analysis and design proposals to prevent fatigue failure due to warping and distortion. In weight-critical beams, the use of ultra-high-strength steels (UHSSs) with yield strengths up to $1100 \mathrm{MPa}$ becomes reasonable. With UHSS grades, hot- or cold-formed profiles are not typically available, and box beams made from welded sheet metals are used instead. In such structures, the fatigue-critical details are the brackets, longitudinal welds, and transverse welds fixing the beam to the end plate.

The present paper introduces an analytical approach to calculate the stresses that can be used in the fatigue 
analysis of a cantilever beam. First, the bi-moment and warping stress distributions along the beam length and over the cross section are obtained and, subsequently, the distortional behavior is established based on the theory of a beam on an elastic foundation (BEF) [13]. Finite element analyses (FEAs) using 2D mid-plane element models are conducted to obtain numerical results for a comparison. In addition, a more detailed analysis of the secondary warping of a square hollow section (SHS) with a round corner is conducted using a 3D solid element model. A fatigue analysis is conducted on the end plate of a cantilever beam using the effective notch stress (ENS) concept [14] and considering both weld toe and weld root fatigue failures. Furthermore, with FE modeling, the effect of a transverse diaphragm plate and its location on the distortion of the cross section is investigated; this is followed by some design recommendations. The work is focused on beams loaded with torsional moment, and therefore, SHS profile is the main focus of this work. In addition, RHSs are also analyzed to provide a comparison with an SHS.

\section{Analytical approach}

\subsection{Geometry, load, and boundary conditions of a cantilever beam}

In this study, the force couple loading $F$ is imposed on pair of brackets at the free end of a cantilever beam, as illustrated in Fig. 1. The other end of the beam is fixed to a stiff end plate, thus representing a completely rigid boundary condition. The loaded end of the beam is provided with a diaphragm plate, preventing the distortion of the cross section in the place where the brackets are fixed to the beam. However, as the plate is very thin, it does not prevent the free warping of the beam in this section.

\subsection{Warping due to torsional loading}

Using the cross-section symbols denoted in Fig. 1, for a thinwalled closed section with constant plate thickness $t$, the torsional moment of inertia $I_{t}$ is

$I_{t}=\frac{4 A_{0}^{2}}{\oint_{s} \frac{d s}{t}}=\frac{4 b^{2} h^{2}}{\sum_{i} \frac{s_{i}}{t_{i}}}=\frac{2 b^{2} h^{2} t}{b+h}$

The warping constant of the cross section $I_{\omega}$ consists of primary and secondary parts, whereby the primary part is calculated based on the sectorial coordinate $\omega$ of the middle line of the cross section and the secondary part is based on the warping over the plate thickness in direction $r_{n}$ for each cross section part.

$$
\begin{aligned}
I_{\omega} & =\oint_{s} \omega^{2} t d s+2 \oint_{s} \int_{r_{n}=0}^{t / 2} r_{n}^{2} s^{2} d r_{n} d s \\
& =\oint_{s}\left(r_{t}-\frac{2 A_{o}}{t \oint_{s} \frac{d s}{t}}\right)^{2} t d s+\oint_{s} \frac{t^{3}}{48} s^{2} d s \\
& =\frac{b^{2} h^{2} t}{24} \frac{(h-b)^{2}}{h+b}+\frac{2\left(b^{3}+h^{3}\right) t^{3}}{144}
\end{aligned}
$$

In the case of SHS, the dimension $h=b$ and, consequently, primary warping is zero; however, except for a rotationally symmetric cross section, there always exists secondary warping, which for an SHS with sharp corners is:

$I_{\omega}=\frac{b^{3} t^{3}}{36}$

In general loading cases, the beam can be subjected to both axial and transverse (shear) loads and thus also bending moments. Nevertheless, the main focus of this
Fig. 1 The studied and analyzed box beam structure

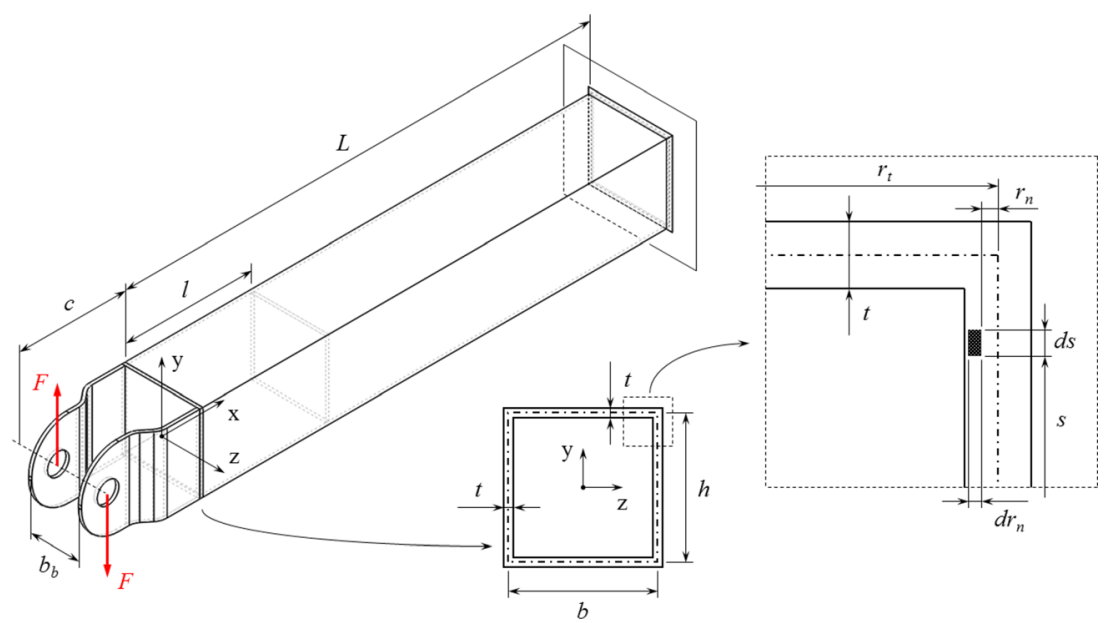


study is on the torsional moment $T$ caused by the couple force $F$ as follows:

$T=F b_{b}$

The torsional moment $T$ in the brackets generates the bimoment $B_{\omega, 0}$ at the loaded end of the beam:

$B_{\omega, 0}=T c=F b_{b} c$

The bi-moment depends on the second derivate of the twisting angle $\theta$ relative to the $x$-axis.

$$
\begin{aligned}
B_{\omega}(x) & =E^{\prime} I_{\omega} \frac{d^{2} \theta}{d x^{2}} \\
& =E\left[\frac{b^{2} h^{2} t}{24} \frac{(h-b)^{2}}{h+b}+\frac{2\left(b^{3}+h^{3}\right) t^{3}}{144\left(1-\nu^{2}\right)}\right] \frac{d^{2} \theta}{d x^{2}},
\end{aligned}
$$

where $E$ and $v$ are the Young's modulus and the Poisson's ratio of material, respectively. The bi-moment of the beam consists of $B_{\omega, 0}$ and the effect of the torsion moment $T$. Considering the present boundary and load conditions, as shown in Fig. 1, the bi-moment distribution $B_{\omega,}(x)$ over the beam length can be defined:

$$
\begin{aligned}
B_{\omega}(x) & =\frac{B_{\omega, 0} \cosh k(L-x)+\frac{T}{k} \sinh k x}{\cosh k L} \\
= & F b_{b} \frac{c k \cosh k(L-x)+\sinh k x}{k \cosh k L},
\end{aligned}
$$

where the torsion constant $k$ is

$k=\sqrt{\frac{G I_{t}}{E I_{\omega}}}=\sqrt{\frac{I_{t}}{2(1+v) I_{\omega}}}$

In Eq. (8), $G$ is the shear modulus of material. At the loaded end of the beam, $B_{\omega, x=0}=F c b_{b}$, and at the fixed end:

$B_{\omega, x=L}=F b_{b} \frac{c k+\sinh k L}{k \cosh k L}$

The bi-moment induces axial stresses in the beam, which consists of membrane stresses due to the primary warping and shell bending stresses due to the secondary warping. For an SHS with sharp corners, the following equations can be derived:

$$
\begin{aligned}
& \sigma_{\omega}(s)=\frac{B_{\omega}(x)}{I_{\omega}} \omega=0 \\
& \sigma_{\omega}\left(s, r_{n}\right)=\frac{36 B_{\omega}(x)}{b^{3} t^{3}} s r_{n}= \pm \frac{9 B_{\omega}(x)}{b^{2} t^{2}}, \text { at }
\end{aligned}
$$

the outer or inner corner of the SHS-profle

This torsional moment $T$ consists of the pure (or uniform) torsion $T_{B r e d t}$ and the warping torsion $T_{\omega}$.
$T=T_{\text {Bredt }}+T_{\omega}=G I_{t} \frac{d \theta}{d x}+E I_{\omega} \frac{d^{3} \theta}{d x^{3}}$

The shear stresses involved in warping can now be defined as

$$
\begin{aligned}
\tau_{\omega} & =\frac{T_{\omega} S_{\omega}}{I_{\omega} t}=\frac{d B_{\omega}(x)}{d x} \frac{S_{\omega}}{I_{\omega} t} \\
& =F b_{b} \frac{\cosh k x-c k \sinh k(L-x)}{\cosh k L} \frac{S_{\omega}}{I_{\omega} t},
\end{aligned}
$$

where $S_{\omega}$ is the sectorial cross section modulus. Based on Bredt's formula, the shear stress is

$$
\begin{aligned}
\tau_{\text {Bredt }} & =\frac{T_{\text {Bredt }}}{2 b h t}=\frac{T-T_{\omega}}{2 b h t} \\
& =\frac{F b_{b}}{2 b h t}\left[1+\frac{c k \sinh k(L-x)-\cosh k x}{\cosh k L}\right]
\end{aligned}
$$

The schematic distributions of internal forces over the beam length and the warping stresses over the cross section area are presented in Fig. 2. In the case of SHS, the bi-moment will occur only at the loaded and fixed ends of the beam.

The secondary warping occurs very locally in the corners of the box section, but it can induce detrimental stresses if the local degree of freedom, involved in the secondary warping, is prevented. This can occur when the wall of the cross section is locally prevented to rotate, e.g., due to joining the beam by welding to a stiff transverse plate component. It is worth noting, however, that the primary warping stresses depend on the global boundary conditions of the beam, while the secondary warping stresses depend on the local boundary conditions of the cross-section wall. Consequently, primary and secondary warping can occur independently on each other. The primary warping of the cross sections with round corners has been investigated analytically by Rubin [8]. In this study, this issue is addressed by means of the FEA in Sect. 3 .

\subsection{Distortion of the beam}

In addition to the warping, the torsional load, causing the local bi-moment at the loaded end of the beam, also establishes a distortional loading. Unlike with the warping, in the distortion, the cross section does not remain in its original form but deforms to a parallelogram shape. Because the corners of the box section are rigid, the distortion causes transverse bending stresses. Both warping and distortion includes longitudinal deformations and stresses, whereby the distributions along the profile perimeter are affine yet disassociated in the longitudinal direction of the beam. Based on the theory of BEF, Fig. 3 shows the longitudinal and transverse 
Fig. 2 a Bi-moment and $\mathbf{b}$ torsional moment distributions over the beam length, $\mathbf{c}$ primary and secondary warping stresses at the corner of an RHS cross section, and $\mathbf{d}$ Bredt's and warping shear stresses in the cross section of an RHS

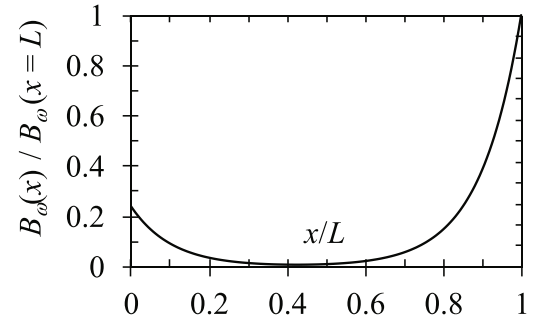

(a)

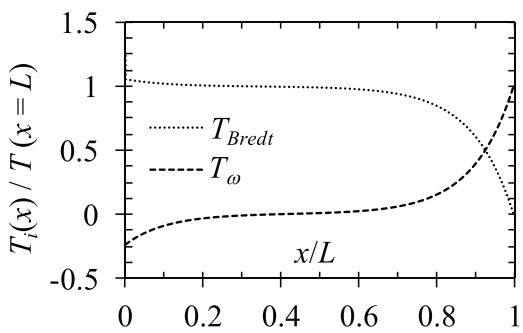

(b)
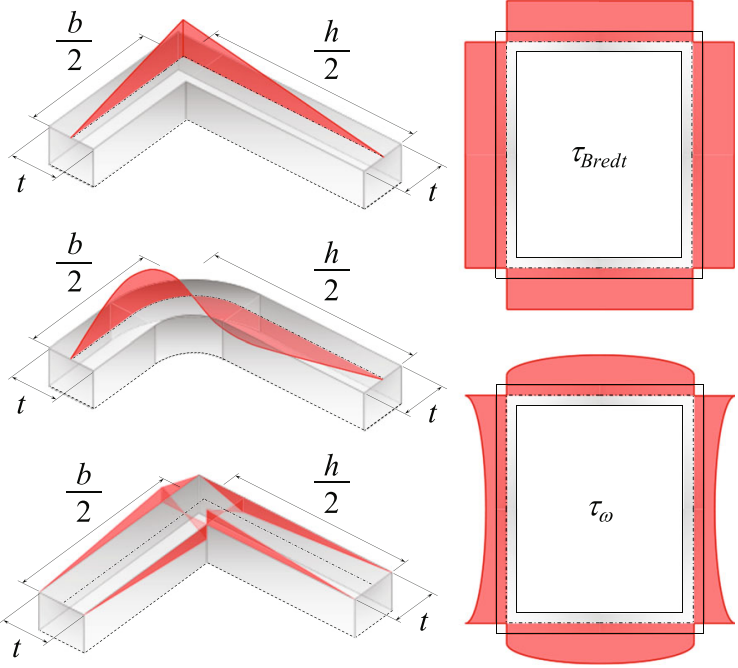

$\sigma_{\omega}$

(c)

(d) distributions of distortion, which are compared in some cases with the results of the numerical analyses described in Sect. 3. The distortional deformation $v(x)$ $\left(=d_{1}-d_{2}\right.$, see Fig. 3$)$ is the difference between the diagonal dimensions of the cross section as defined by the deformed geometry. The distortional deformation in the longitudinal direction of the SHS beam with a semiinfinite length can be determined based on the theory of BEF [15]:

$v(x)=\frac{12 \sqrt{2} e^{-\beta x} \sin \beta x}{\beta^{2} E t b^{3}} F c$,
Fig. 3 Distortion of the SHS beam $(L=4000 \mathrm{~mm})$ with a cross section with the dimensions $240 \times 240 \times 4 \mathrm{~mm}$ loaded with a force couple of $F=150 \mathrm{kN}\left(b_{b}=\right.$ $240 \mathrm{~mm}, c=100 \mathrm{~mm}$ ); based on the theory of BEF: a distortional deformation, $\mathbf{b}$ transverse bending stress $\left(\sigma_{b}\right)$ at the corner, and $\mathbf{c}$ longitudinal membrane stress $\left(\sigma_{v}\right)$ at the corner, obtained following the analytical approach and FEA. Further details regarding the FEAs can be found in Sect. 3 (a)

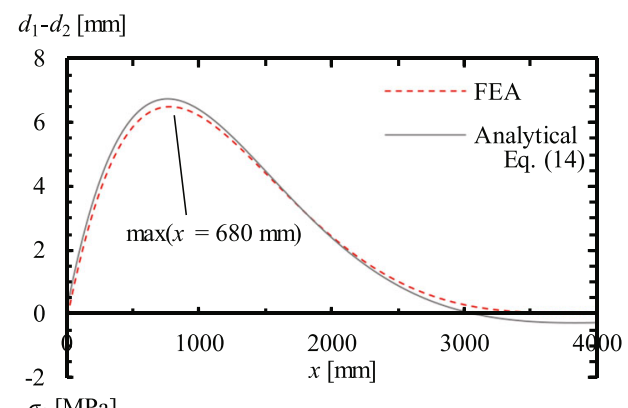

(b)

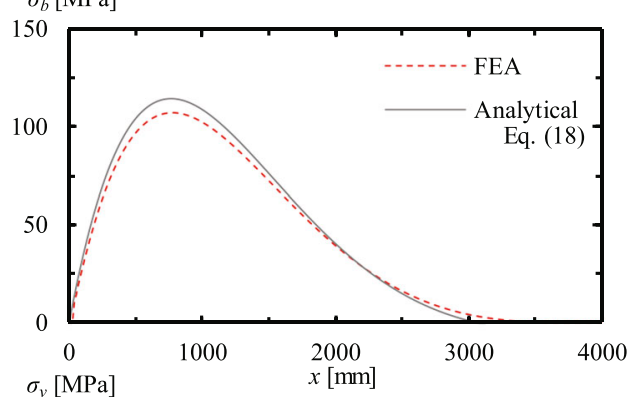

(c)

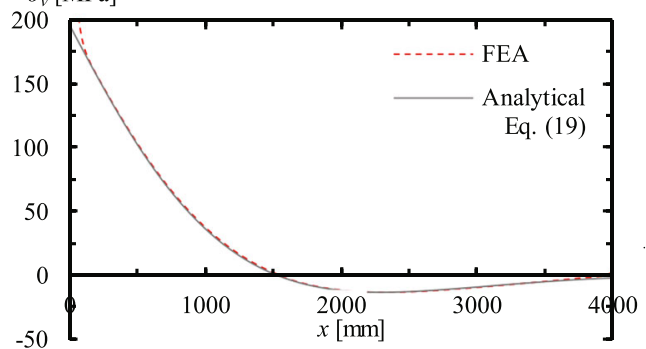

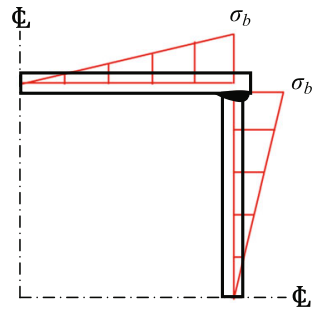
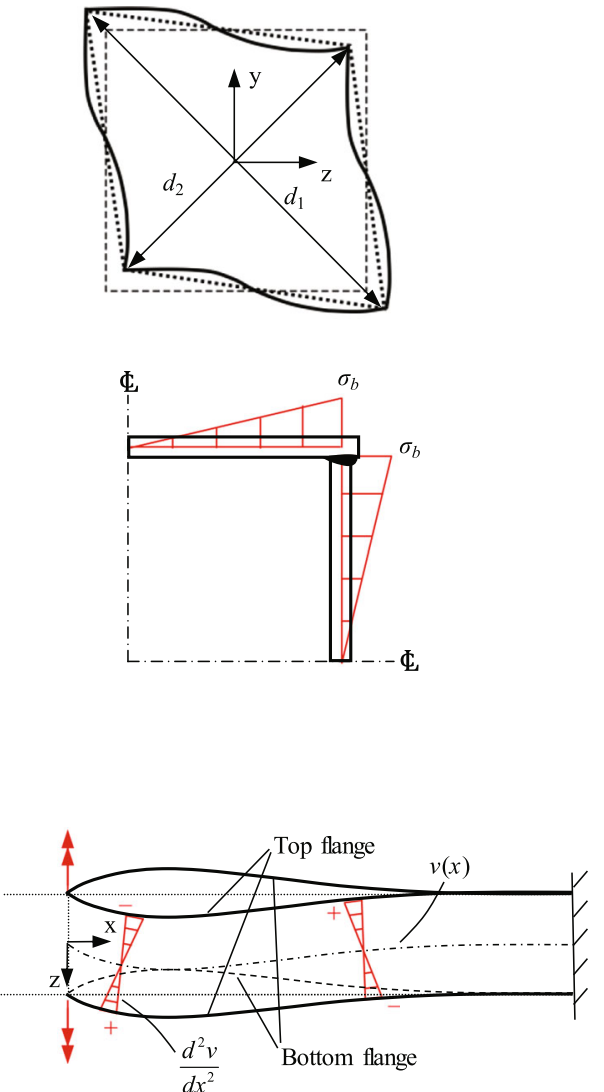
Fig. 4 Dimensions of the SHS beam used in the FEA

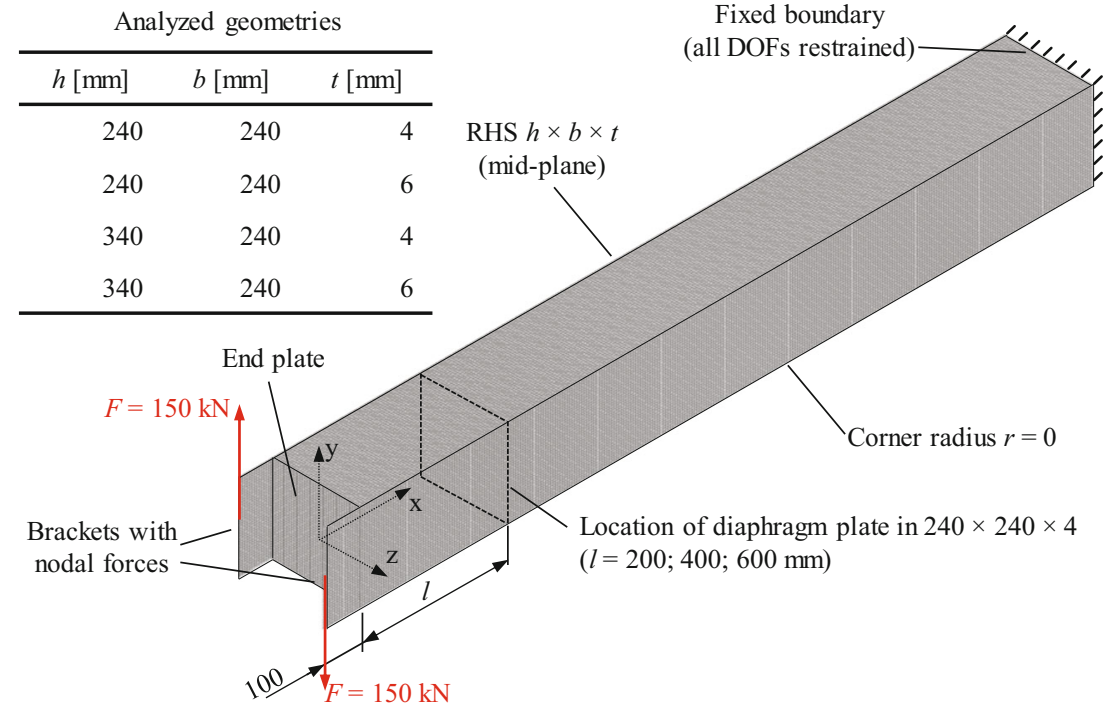

where

$\beta=\sqrt[4]{\frac{12 t^{2}}{b^{6}\left(1-\nu^{2}\right)}}$

The elastic foundation constant $f$ for the BEF approach can be defined by analyzing the cross section as a continuous frame and calculating the transverse stiffness of the frame based on the unit force-displacement-method.

$f=\frac{4 E t^{3}}{b^{3}\left(1-\nu^{2}\right)}$

The maximum deformation $v_{\max }$ occurs when

$$
\begin{aligned}
\frac{d v}{d x} & =\frac{4 \sqrt{2} \beta^{2} e^{-\beta x}(\sin \beta x-\cos \beta x)}{f} F_{C}=0 \rightarrow \tan \beta x \\
& =1 \rightarrow x_{v_{\max }}=\frac{\arctan 1}{\beta}=\frac{\pi}{4 \beta}=\frac{\pi}{4} \sqrt[4]{\frac{1-\nu^{2}}{12}} \sqrt{\frac{b}{t} b}
\end{aligned}
$$

If the distortion occurs due to fluctuating torsion, it can be a detrimental phenomenon leading to the fatigue of longitudinal welds if they are located in the corners of the box beam. The longitudinal welds (all or at least some) are typically prepared using single-sided welding and, thus, the weld root fatigue capacity may become a critical design criterion. The phenomenon can be diminished through the use of diaphragm plates; however, this effect only occurs locally. Naturally, the first diaphragm plate is located at the fixing point on the brackets, at the loaded end of the beam. However, this plate prevents the distortion of the cross section only at that position. Along the beam, the distortion $v(x)$ increases according to Eq. (14), reaching a maximum at the distance of $\pi /(4 \beta)$ and, subsequently, fading gradually. A simple engineering design concept could indicate placing of a second diaphragm at precisely the place of maximum distortion. Theoretically, the optimal location for an additional diaphragm could be determined using the theory presented by Hetényi [13], but this requires
Fig. 5 a General overview of normal stresses due to secondary warping in a sharp corner of an SHS and $\mathbf{b}$ distributions of the same stresses along the inner, middle, and outer surfaces of the profile [17]

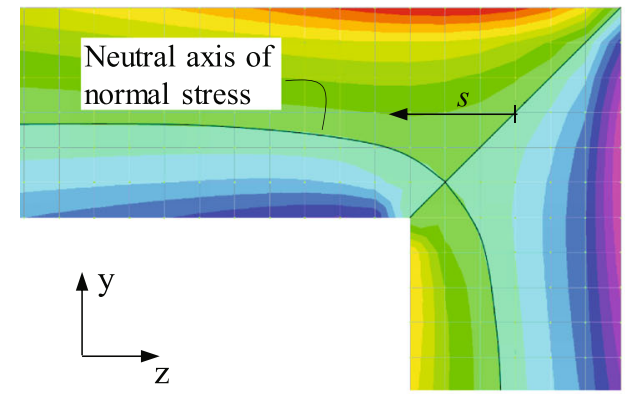

(a)

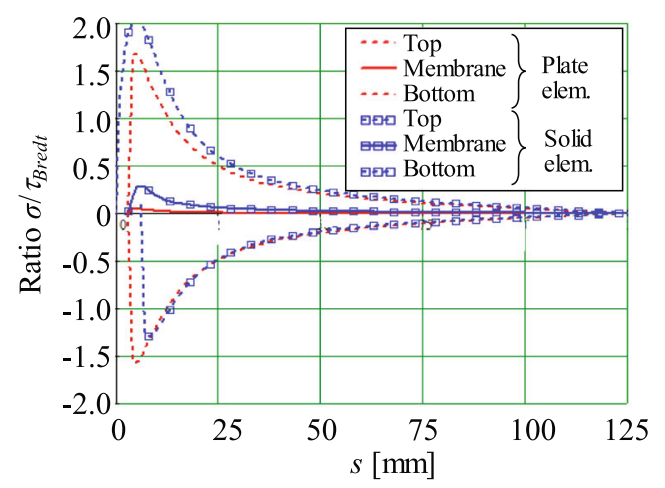

(b) 
Fig. 6 a Axial stress distribution at the fixing point and $\mathbf{b}$ the effect of the corner radius to height ratio on the degree of warping of the SHS $150 \times 150 \times 8[17]$

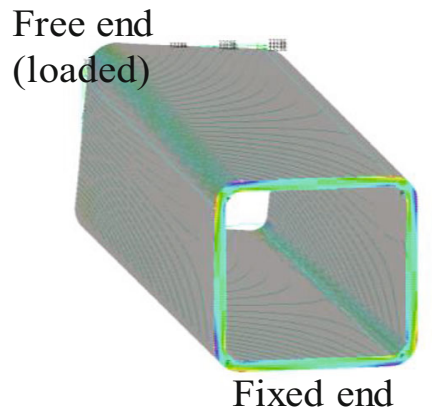

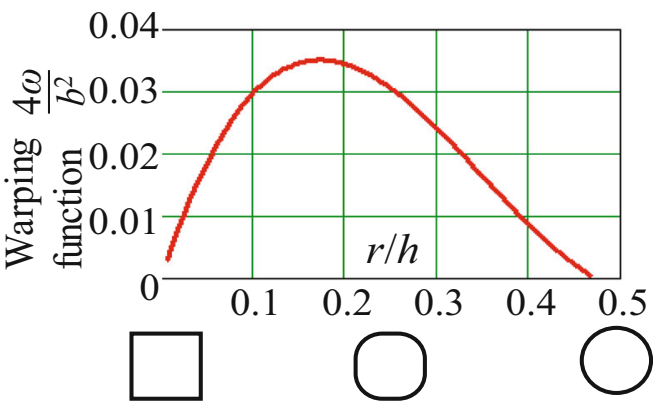

(b) very complicated analytical formulation and is, therefore, ignored here. However, the optimal location of the second diaphragm plate is investigated numerically by means of FEAs in Sect. 3.

The transverse bending stress $\sigma_{b}(x)$ follows the distribution of distortional displacement $v(x)$ and is

$\sigma_{b}(x)=\frac{3 E t}{2 \sqrt{2} b^{2}\left(1-\nu^{2}\right)} v(x)$

(a) and, thus, $E=210 \mathrm{GPa}$ and $v=0.3$. Linear 4-noded plate element (CQUAD4) models with linear static analyses are carried out using NxNastran as a solver. More detailed descriptions of the models and analyses are given by Ahlfors [16, 17]. A beam length of $L=2000 \mathrm{~mm}$ was used as the basis in the analyses. However, to validate the analytical approach (see Sect. 2), in which a semi-finite beam was assumed, an $L=$ $4000 \mathrm{~mm}$ model $(240 \times 240 \times 4)$ was analyzed to also take the damping effect $\left(\mathrm{e}^{-\beta x}\right)$ into account in the FEA. The results of those analyses are presented in Fig. 3. Furthermore, linear 8noded solid element (CHEXA) models were used to investigate the secondary warping of the cross section and to analyze the welded end plate detail using the ENS concept. The element mesh models used in the analyses can be found in Sect. 3.2 .

\subsection{Warping of the cross section}

In an SHS beam with sharp corners, the deformations and stresses due to primary warping are zero. However, secondary warping occurs at the fixed end of the beam. A general overview of the normal stress distribution in the fixed corner and the same stress distribution in the inner, middle, and outer surfaces of the profile face derived using both plate and solid elements are shown in Fig. $5 \mathrm{a}$ and b, respectively. The

The FE model for a beam with the load and boundary conditions is shown in Fig. 4. The beam is made of steel material

\section{Numerical analysis}

\subsection{FE model}

Fig. 7 Membrane stress to shear stress ratio for a SHS $150 \times 150 \times$ 8 and b RHS $200 \times 100 \times 8$ beams subjected to pure torsion loading [17]. Parameter $s$ is the distance along the center line of profile perimeter and the stress distribution is presented for one quarter of the whole cross section

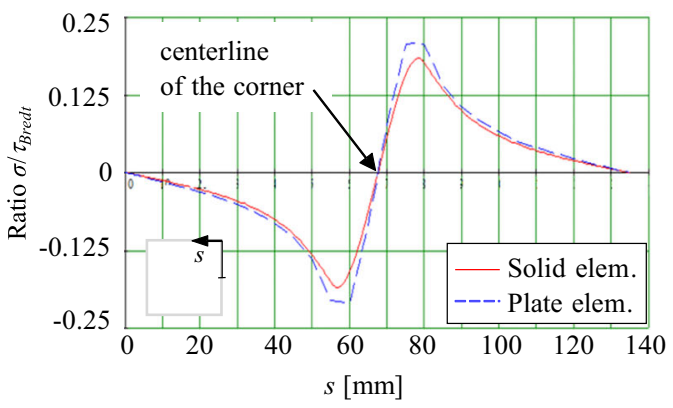

(a)

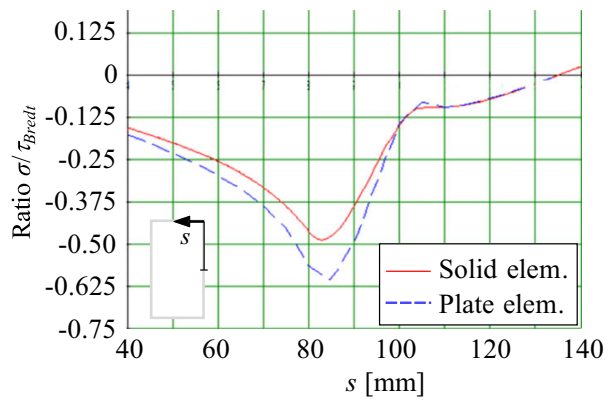

(b) 
Fig. 8 a SHS detail analyzed with the ENS method and $\mathbf{b}$ the dimensions of the analyzed SHS profile (modified from [17])

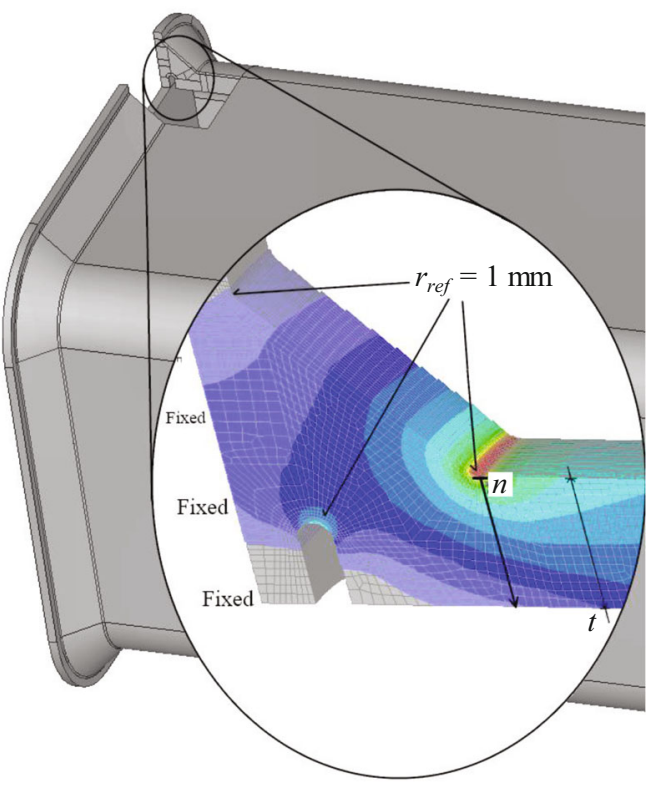

(a)

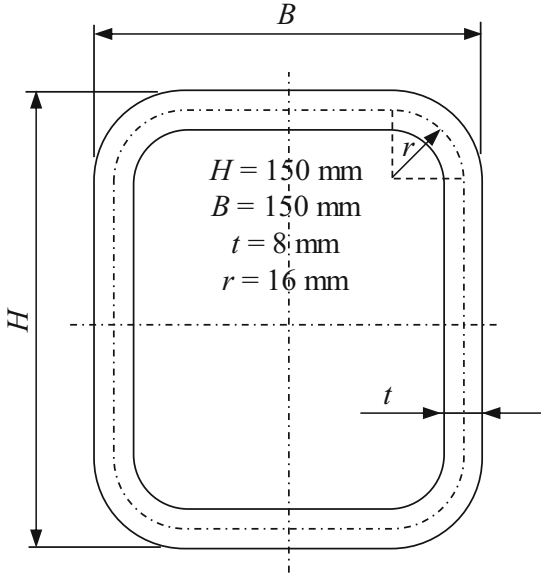

(b) adjacent normal stress components in the horizontal and vertical plates are opposite and, thus, induce high local shear stresses in the corner acting parallel to the longitudinal axis of the beam. The normal and shear stresses occur only locally and have no impact on the static capacity of such a beam structure, but they must be considered in fatigue analysis because they can have a remarkable negative role on the structural performance and durability.

If the box section has round corners, there also exist, in addition to secondary (bending) stresses, primary (membrane) stresses due to the warping of the SHS. Figure 6 depicts the typical stress distribution of an SHS profile and the effect of the corner radius to beam height ratio on the degree of primary warping in the corner area. If the corner radius to height ratio of profile $(r / h)$ approaches zero, the primary warping will vanish, and if the ratio approaches a value of 0.5 , all warping will vanish. Figure $6 \mathrm{~b}$ shows that the maximum warping is reached when $r / h=0.18$.
Figure 7 shows the ratio of normal stress to Bredt's shear stress along the profile perimeter for the SHS and RHS profiles. It can be seen that in the corner area, the axial membrane stresses can be approximately half the shear stresses.

To consider the fatigue of the SHS with a round corner, the effective notch stress (ENS) concept [14] was applied to a 3D geometry, with modeled welds and a reference radius of $r_{r e f}=$ $1.0 \mathrm{~mm}$ at the weld toe and root, in the joint where the highest axial stress occurs, as illustrated in Fig. 8a. The dimensions of the profile are given in the Fig. $8 \mathrm{~b}$.

The results of the analyses are presented in Fig. 9. The weld throat thickness $a \approx 1.1 t$ was equal in all FE models, but the degree of penetration was varied so that the models represented joints with fully and half penetrated as well as pure fillet welds. In all cases, the weld toe is the critical part of the joint, not the root side. Consequently, the stress distributions over the plate thickness are presented only at the weld toe. The presented distributions
Fig. 9 Stress ratio distributions over the plate thickness at the weld toe with different degrees of penetration: a full penetration, $\mathbf{b}$ half penetration, and $\mathbf{c}$ pure fillet weld [17]

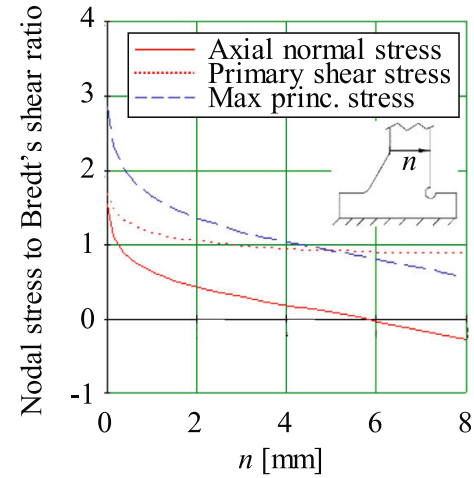

(a)

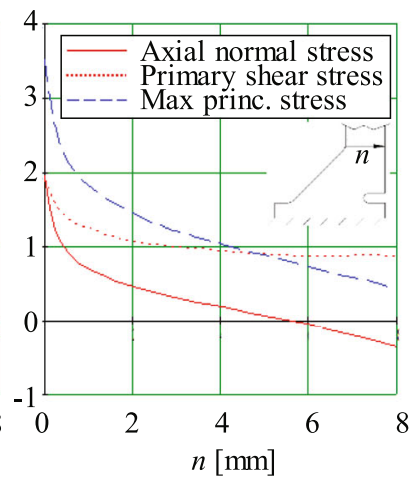

(b)

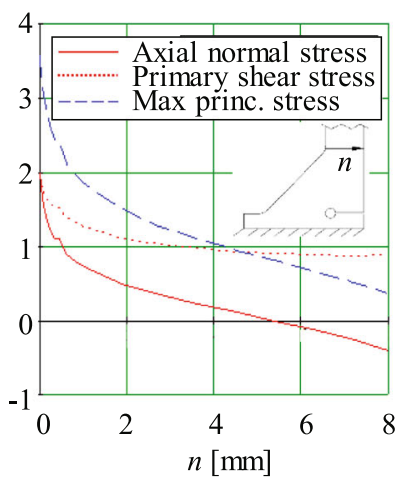

(c) 


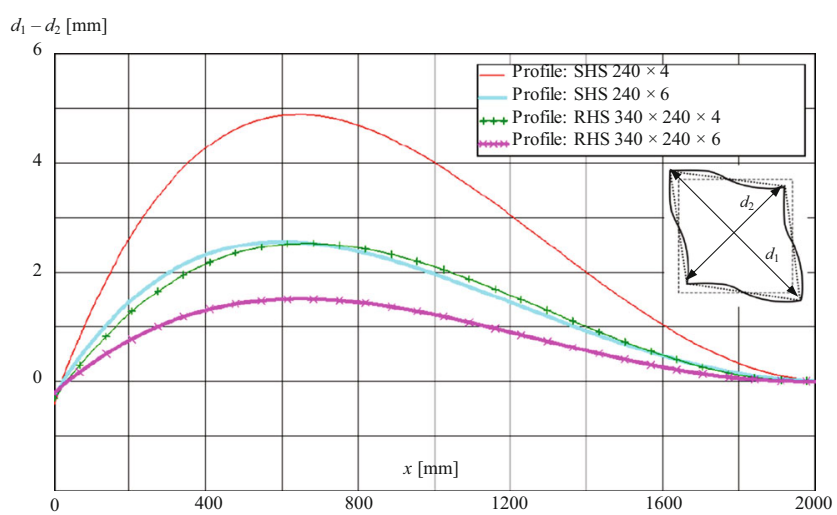

Fig. 10 Effect of the profile cross section dimensions on the distortion of the beam [16]

are normalized by dividing the normal stresses by Bredt's shear stress.

\subsection{Distortion of the cross section}

In Fig. 10, the deformations for different profile sizes are presented for a beam length of $2000 \mathrm{~mm}$.

In Fig. 10, it can also be seen that some of the distortions of the beam are at the location of the first diaphragm plate $(x=0)$. This is due to the shear deformation of the diaphragm plate, of which thickness is $t_{p}$.

$v_{0}=\gamma b=\frac{\tau b}{G}=\frac{F b}{G h t_{p}}=\frac{150000 \cdot 240}{80000 \cdot 240 \cdot 4}=0.47 \mathrm{~mm}$

Figure 11 presents the effect of the plate thickness $t$ on the distortional deformation of the SHS profile with the dimensions $240 \times 240 \times t$. A $50 \%$ increase in the plate thickness decreases the deformation nearly by approximately $50 \%$. This cannot be concluded directly from Eq. (14) since the thickness $t$ is involved in the $\beta$ parameter.

Figure 11 also demonstrates the effect of the location of the second diaphragm plate in the SHS beam with the aforementioned dimensions. The optimum location for the distance seems

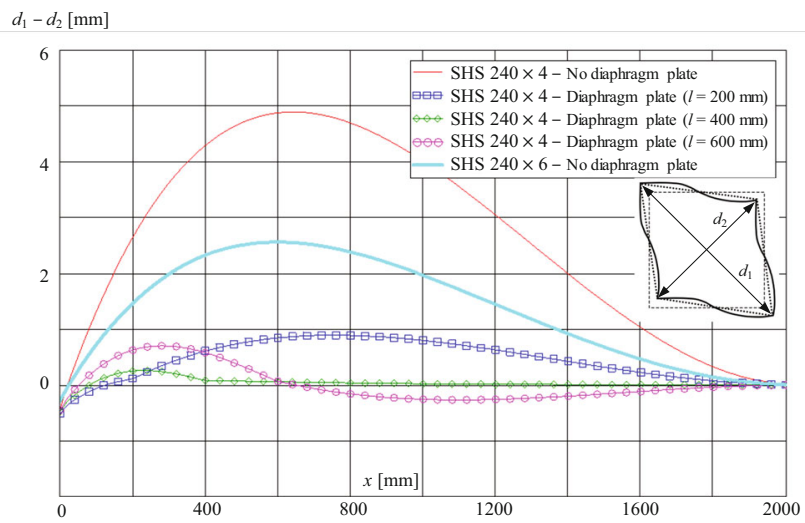

Fig. 11 Effect of plate thickness and the location of the second diaphragm plate on the distortion of the cross section [16] to be roughly the dimension of the beam height. Figure 12 shows the effect of diaphragm plates on the axial stresses of the SHS and RHS beams. The transverse plates slightly prevent the warping deformation, acting as internal springs for the bi-moment, but locally, they prevent the distortion efficiently.

\section{Discussion}

The normal and shear stresses due to warping and distortion cannot be neglected in structures subjected to torsional loading. Distortion should always be considered in the analysis of flexibility, stability, fatigue, and ultimate capacity of joints with hollow sections. In the present paper, the distortion and warping behavior of SHS and RHS members subjected to torsional moment were investigated analytically on the basis of theoretical model for stress analysis and, numerically, conducting FEAs.

The length of a beam structure plays a crucial role in the warping and distortion distributions along the beam length. In RHS beams, the primary warping is typically rather small (if $h / b$ $<2$ ) and the local peak value occurs only at the loading and fixing points of beam, as illustrated in Fig. 2. The distortion has its maximum at distance of $0.412 b \sqrt{ }(b / t)$, after which it fades very smoothly, as illustrated in Fig. 3. Even a 4000-mm-long beam with the cross-section dimensions $240 \times 240 \times 4 \mathrm{~mm}$ is not long enough to completely eliminate the distortional deformations and stresses. This causes small differences between the theoretical model and the FEA, see Fig. 3, but generally, the agreement between the analytical and FEA calculations is good.

Stresses due to warping and distortion can have a remarkable effect on the fatigue performance of a beam subjected to cyclic or fluctuating torsional loading. The primary warping, due to the round corner together with secondary warping, can cause fatigue failures even in the case of SHS, as shown in Fig. 13a. The distortion-induced cyclic transverse bending stresses, see Fig. 3b and Eq. (18), can also cause fatigue failures longitudinally at the corner of SHS members, as demonstrated in Fig. 13b. Particularly, in the case of UHSS materials, fillet-welded hollow sections are fabricated for steel constructions, e.g., in boom components, due to the lack of tubular members made of high- and ultra-high-strength steel grades. In such welded details, lack of weld penetration and sharp transition at the weld root expose the longitudinal welds for weld root fatigue failures. Consequently, careful consideration of cyclic torsional loads in the stress analysis is particularly required in welded box beams. In Ref. [18, 19], fatigue failures in an SHS with an end plate, and subjected to the cyclic torsional moment, were found due to the warping and distortion. Nevertheless, these studies did not address the warping behavior in more detail.

The diaphragm plate at the loaded end of the beam does not prevent distortion, although it does curtail it locally. When considering the optimal location for stiffeners and diaphragm plates, 
Fig. 12 Longitudinal membrane stresses $\left(\sigma_{v}\right)$ for a SHS $240 \times$ $240 \times t$ and b RHS $340 \times 240 \times t$ [16]

Fig. 13 Warping-induced fatigue failures in a SHS beam with the cross section dimensions of $100 \times 100 \times 5 \mathrm{~mm}$ subjected to cyclic torsional loading: a fatigue failure at the weld toe of an end plate and $\mathbf{b}$ longitudinal fatigue crack at the corner of a SHS member [18]

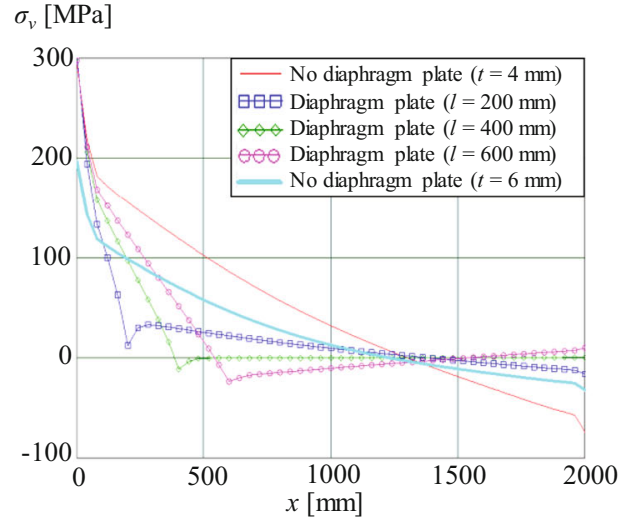

(a)

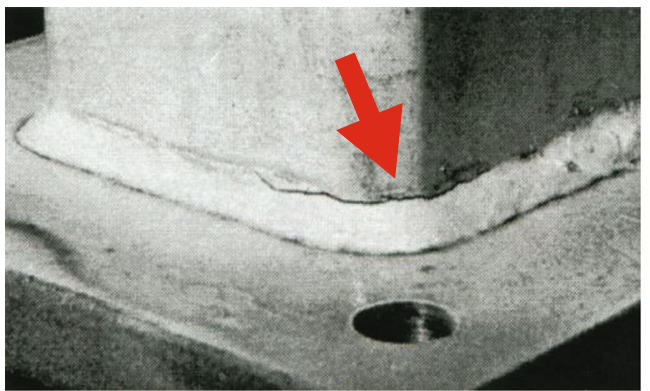

(a)

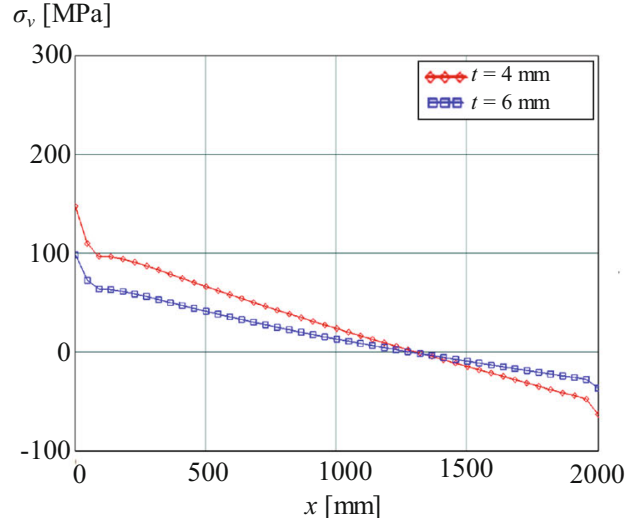

(b)

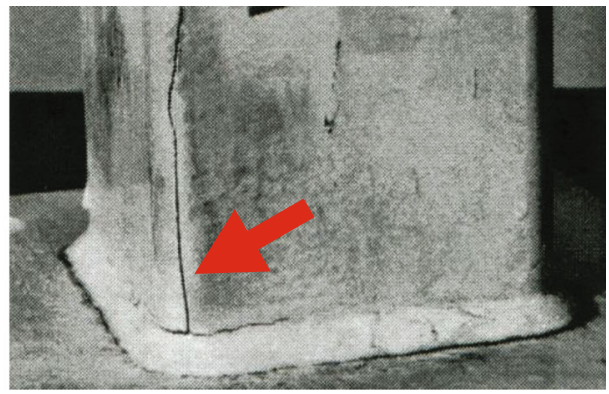

(b) these are usually located where the maximum deformation occurs without such stiffener, see Eq. (17). On the basis of the results of this study, see Fig. 11, this approach is not applicable when considering the warping behavior. If diaphragm plates are located too far from each other, the distortion occurs between the diaphragm plates, and if they are too close, the effectiveness of the second plate is insufficient. The second plate after the end plate is important because it creates a transverse torsion bar inside the beam, which connects the torsional couple moments. The stiff torsion bar efficiently destroys the bi-moment induced by the couple forces in the brackets. A transverse bar in the shape of any closed hollow section, as illustrated in Fig. 14, is stiff and will efficiently eliminate the bi-moment loading by causing torsion shear stresses in the transverse box. This grounding spring effect is addressed in greater detail in Ref. [20]. The effectiveness is based on the torsional stiffness $S_{t, p}$ of the transverse beam created by these diaphragm plates and can be evaluated using the following equation:

$S_{t, p}=\frac{G I_{t}}{b}=\frac{2 G h^{2} l^{2}}{b\left(\frac{h}{t_{p}}+\frac{l}{t}\right)}$

The recommended distance for the second diaphragm plate still enables the welding, also in a case of commercially available
Fig. 14 The bi-moment is grounded by a square or $\mathbf{b}$ circular shapes, which can be created by diaphragm plates, separate tubes, or castings

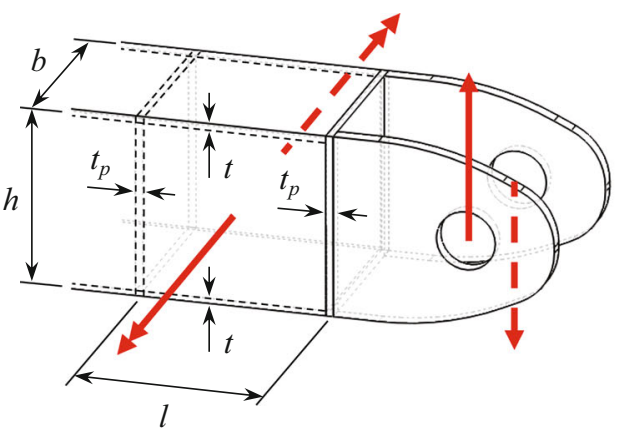

(a)

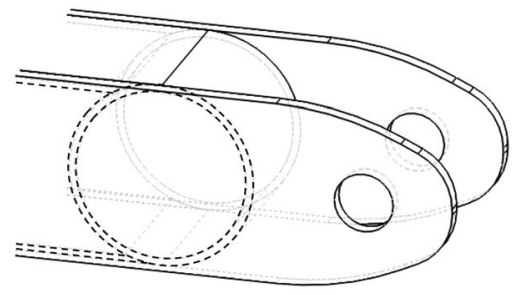

(b) 
RHS beams. If the box section is self-made design, the diaphragm can be welded from three sides before closing the section, which also enables longer distance for the second diaphragm.

\section{Conclusions}

Based on the theoretical and numerical analyses along with experimental findings from the literature, the following conclusions can be drawn:

- Primary warping (causing either axial membrane stresses or deformations) occurs also in SHSs with round corners.

- Primary and secondary warping should be considered in the fatigue analysis of SHSs subjected to fluctuating torsional loading, particularly at the rigid fixed end.

- Distortion can have effect on the flexibility, stability, and ultimate capacity of joints, also in static loading.

- Transverse bending stresses due to distortion can have a negative impact on the fatigue performance of beams with hollow cross sections, especially if the fixing welds are located in the corners of the cross section.

- A diaphragm plate located only at the loaded end does not prevent distortion in a beam.

- A second diaphragm plate efficiently decreases the distortion if it is located at a distance of approximately the height of the beam from the end plate.

- In the fillet-welded detail at the fixed end, higher stresses resulted at the weld toe than at the weld root, also in pure fillet welds with no penetration.

Acknowledgments Open access funding provided by LUT University. The authors wish to thank Business Finland for funding the ISA-LUTproject and, hence, for enabling this research work to be completed.

Open Access This article is licensed under a Creative Commons Attribution 4.0 International License, which permits use, sharing, adaptation, distribution and reproduction in any medium or format, as long as you give appropriate credit to the original author(s) and the source, provide a link to the Creative Commons licence, and indicate if changes were made. The images or other third party material in this article are included in the article's Creative Commons licence, unless indicated otherwise in a credit line to the material. If material is not included in the article's Creative Commons licence and your intended use is not permitted by statutory regulation or exceeds the permitted use, you will need to obtain permission directly from the copyright holder. To view a copy of this licence, visit http://creativecommons.org/licenses/by/4.0/.

\section{References}

1. Vlasov VZ (1949) Строительная механика тонкостенных пространственных систем (in Russian)
2. Vlasov VZ (1963) Thin-walled elastic beams. Israel Program for Scientific Translations, Jerusalem

3. Murray NW (1984) Introduction to the theory of thin-walled structures. Oxford University Press, New York

4. Roik K, Sedlacek G (1966) Theorie der Wölbkrafttorsion unter Berücksichtigung der sekundären Schubverformungen Analogiebetrachtung zur Berechnung des querbelasteten Zugstabes 2:43-52

5. Kollbrunner CF, Hajdin N (1975) Dünnwändige Stäbe, Band 2: Stäbe mit deformierbaren Querschnitten Nichtelastisches Verhalten dünnwandiger Stäbe. doi: https://doi.org/10.1007/9783-662-06782-6

6. Björk T (1989) Secondary warping constant of a beam subjected to torsional load (in Finnish). J Struct Mech 21:3-24

7. Rubin H (2005) Wölbkrafttorsion von Durchlaufträgern mit konstantem Querschnitt unter Berücksichtigung sekundärer Schubverformungen. Stahlbau 74:826-842

8. Rubin H (2007) Torsions-Querschnittswerte für rechteckige Hohlprofile nach EN 10210-2 : 2006 und EN 10219-2 : 2006. Stahlbau 76:21-33. doi: https://doi.org/10.1002/stab.200710004

9. Křístek V (1979) Theory of box girders. John Wiley \& Sons Ltd, Prague

10. Kř́stek V, Škaloud M (1991) Developments in civil engineering, 32: advanced analysis and design of plated structures. Elsevier Science Publishing Company, New York

11. Kähönen A, Niemi E (1986) Distortion of a double symmetric box section subjected to eccentric loading - using the beam on elastic founding approach. Research report. Lappeenranta University of Technology, Lappeenranta

12. Schardt R (1989) Verallgemeinerte Technische Biegetheore. doi: https://doi.org/10.1007/978-3-642-52330-4

13. Hetényi M (1946) Beams on elastic foundation - theory with applications in the fields of civil and mechanical engineering. University of Michigan Press, Ann Arbor

14. Sonsino CM, Fricke W, De Bruyne F et al (2012) Notch stress concepts for the fatigue assessment of welded joints - background and applications. Int J Fatigue 34:2-16. https://doi.org/10.1016/j. ijfatigue.2010.04.011

15. Ylinen A (1976) Elasticity and strength of materials (in Finnish). Part I., 2nd edition. WSOY, Porvoo, Finland

16. Ahlfors M (2014) Design of a box girder againts distortion and torsional load (in Finnish). Lappeenranta University of Technology, Bacherlor's thesis

17. Ahlfors M (2015) Distortion and internal warping torsion of a double symmetric hollow section. Master's thesis. Lappeenranta University of Technology, Lappeenranta

18. Tong L (2007) The influence of variable amplitude loading on the fatigue strength of RHS corners. Master's thesis. Lappeenranta University of Technology, Lappeenranta

19. Bäckstrom M (2003) Multiaxial fatigue life assessment of welds based on nominal and hot spot stresses VTT Publications 502

20. Björk T (1991) On the spring constant in open section joints. In: Niemi E (ed) Proc. 4th Finnish Mech. Days. Lappeenranta, pp 351360

Publisher's note Springer Nature remains neutral with regard to jurisdictional claims in published maps and institutional affiliations. 